\title{
Can We Rely on mDixon Technique on Quantification of Hepatic Steatosis?
}

\author{
MONA ZAKY, M.D.* and HATEM ELALFY, M.D.** \\ The Departments of Diagnostic Radiology* and Gastroenterology \& Hepatology**, Faculty of Medicine, Mansoura University
}

\begin{abstract}
Background: Non-Alcoholic Fatty Liver Disease (NAFLD) is currently the outstanding cause of chronic liver disease. Magnetic Resonance (MR) is widely used in clinical trials to noninvasively quantify liver fat content.

Aim of Study: To determine the accuracy of mDixon MR technique in quantification of liver fat and correlate the results with liver biopsy.

Material and Methods: A prospective study was conducted at Mansoura University Hospitals between March 2017 to November 2018. This study included forty two patients who were referred from gastroenterology clinic for non-hepatic complaints. Clinical examination and estimation of body mass index was recorded in all patients. Abdominal ultrasonography was done to all patients only to exclude focal lesions and gross morphological changes, then MRI evaluation of the upper abdomen using the mDixon protocol. Within a week interval period, patients had liver biopsy.
\end{abstract}

Results: There was good correlation between the MR estimation of liver fat and histological grading, yielding sensitivity of $83.3 \%$ and specificity of $85.7 \%$ with accuracy of $84.62 \%$ at cut off point of 14.545 .

Conclusion: MR estimation of the liver using mDixon technique provided specific information about liver fat, correlated well with the histological grading. Non invasive technique, does not require ionising radiation hence recommended as method of choice of liver fat quantification.

Key Words: mDixon - MRI liver - Non alcoholic fatty liver.

\section{Introduction}

NON-ALCOHOLIC Fatty Liver Disease (NAFLD) is emerging as a major health disability in patients attending gastroenterology clinics. Apart from alcohol abuse and the hepatitis, nutrition related alcoholic diseases contribute significantly to this category of patients [1].

Correspondence to: Dr. Mona Zaky, The Department of Diagnostic Radiology, Faculty of Medicine,

Mansoura University
Non-Alcoholic Fatty Liver Disease (NAFLD) ranges from simple steatosis to NAFLD-related liver cirrhosis and is a main cause of chronic liver diseases, which is characterized by hepatocyte injury, inflammation, and can further progress into more advanced stage of fibrosis/cirrhosis $[2,3]$ NASH also increases the risk of liver cancer development as well as death from cardiovascular disease [4-6]. No specific biochemical or serological tests for the diagnosis of NAFLD that we know are available at this time. Liver biopsy remains the reference method to accurately diagnose hepatic steatosis. However, among the several limitations of liver biopsy are its invasiveness and potential for bleeding and perforation. In addition, sampling error and interobserver diagnostic variability have also been reported [7].

Ultrasonography (US) and Computed Tomography $(\mathrm{CT})$ can be useful in the detection of fatty liver. However, US and CT have limited ability for quantifying hepatic fat content. Therefore, new non-invasive diagnostic modalities are needed to detect and quantify hepatic steatosis in the whole liver as an alternative to liver biopsy [8] .

MRI has emerged as a reliable option for noninvasive estimation of liver fat. Varieties of MR techniques, like magnetic resonance spectroscopy, conventional in-phase and opposed phase imaging, conventional fat suppression imaging of liver fat and complex chemical shift based water-fat suppression methods have provided various options for assessing fat $[\mathbf{9 , 1 0 ]}$. Each methodology with its merits and limitations has been tried as practical options for estimation of liver fat. mDIXON is one MRI technique which evaluates fat fraction of the liver. This study was envisaged to validate mDixon MRI as an effective method of liver fat assessment and compare the results with earlier evaluation 
methods like liver fat estimation by liver biopsy [11].

\section{Material and Methods}

A prospective study was conducted at Mansoura University Hospitals between March 2017 to November 2018 . The study was approved by the Institutional Review Board. Patients were referred from Gastroenterology Clinic for non-hepatic complaints. Patients included also consisted of liver donors (4 patients, $9.52 \%$ of patients). Written informed consent was taken by all patients.

\section{Inclusion criteria:}

1- Available final diagnosis with pathologic proof as a standard.

2- Patients who will agree to join the study according to the ethical considerations and consent will be taken from them.

\section{Exclusion criteria:}

1- Patients who have cochlear implant.

2- Patients with liver cirrhosis, alcoholic liver disease, bleeding tendency and claustrophobia were excluded from the study.

3- Patients who have implanted neural stimulator.

4- Patients with a heart pacemaker or cardiac defibrillator.

5- Patients with severe claustrophobia.

6- Pregnant patients.

7- Patients contraindicated to contrast media as patients with allergy to it or patient with sever hepatic or renal dysfunction.

Our study included 42 patients (18 males \& 24 females), the mean age of the male patients was $49.67 \pm 2.89$ years, the mean age of the female patients was $44.63 \pm 11.76$ years, the mean height of male patients was $178.17 \pm 5.77 \mathrm{~cm}$, while the mean height of female patients was $164.0 \pm 5.21 \mathrm{~cm}$. The mean weight of male patients was $96.17 \pm 5.23$ $\mathrm{kg}$, while the mean weight of female patients was $85.38 \pm 9.38 \mathrm{~kg}$. The mean BMI of male patients was $30.30 \pm 2.23$, while the mean BMI of female patients was $31.78 \pm 3.86 .6$ male \& 6 female patients of our study had HTN, 9 female patients had DM. None of male or female patients had HCV Ab or HBS Ag. 3 female patients have ANA. The mean SGPT value of male patients was $65.67 \pm 19.35 \mathrm{U} / \mathrm{L}$, while the mean value of females was $91.39 \pm 66.3$ $\mathrm{U} / \mathrm{L}$, the mean SGOT value of male patients was $67.0 \pm 23.15 \mathrm{U} / \mathrm{L}$, while the mean value of females was $74.58 \pm 41 \mathrm{U} / \mathrm{L}$. The mean value of serum albu- min in male patients was $4.12 \pm 0.47 \mathrm{~g} / \mathrm{dL}$, while its mean value in female patients was $3.98 \pm 0.19 \mathrm{~g} / \mathrm{dL}$. The mean value of serum bilirubin in male patients was $1.09 \pm 0.023 \mathrm{mg} / \mathrm{dL}$, while its mean value in female patients was $1.045 \pm 0.21 \mathrm{mg} / \mathrm{dL}$. The mean value of INR in male patients was $1.12 \pm 0.05$, while its mean value in female patients was $1.14 \pm 0.11$. Ultrasound findings detected fatty liver in 12 male patients \& 21 female patients. The mean fat fraction percent measured by mDixon was $21.51 \pm 16.43 \%$ with median value of $15.21 \%$ in male patients and $17.99 \pm 13.1 \%$ in female patients with median value of $14.02 \%$. The mean value of percent of steatosis (by liver biopsy) was in male patients $28.33 \pm$ $19.40 \%$ with median value of $27.5 \%$ while the mean value was $25.63 \pm 15.83 \%$ in female patients with median value of $17.5 \%$. Core needle biopsy results revealed no steatosis in 3 female patients, minimal steatosis Fig. (3) in 9 male patients and 7 female patients, mild steatosis Figs. $(1,2)$ in 6 male patients and 12 female patients, moderate steatosis in 3 male patients and 2 female patients (Table 1).

Clinical examination and estimation of body mass index was recorded in all patients. Abdominal ultrasonography was done to all patients only to exclude focal lesions and gross morphological changes, then MRI evaluation of the upper abdomen using the mDixon protocol. Within a week interval period, patients had liver biopsy. An estimated percentage of fat by mDixon method and histological grading by liver biopsy were correlated.

MRI examination of liver was done with a 1.5 T Ingenia MR system (Philips Healthcare, Netherlands). 16-channel phased-array body coil was used for this acquisition. The patients were examined in the supine position. An anatomic imaging of entire upper abdomen was performed with axial, free-breathing single-shot Turbo Spin Echo (TSE) sequence. A mDIXON sequence package was used to acquire fat and water images of entire liver. The mDIXON technique combines 2-point DIXON method with flexible echo times. The imaging parameters were: Field of view, $35-40 \mathrm{~cm}$; matrix, 2243 160; bandwidth, $125 \mathrm{kHz}, 3 \mathrm{D}$ T1-FFE sequence, 2 -echoes: TE $1=1.8 \mathrm{msec}, \mathrm{TE} 2=4.0 \mathrm{msec}$, Flip angle $=15, T R=5.2 \mathrm{msec}$, SENSE parallel imaging with acceleration factor 2.0 in phase-encoding direction.

Breath-hold duration was 11 seconds, Axial volume was acquired and 34 slices $(6 \mathrm{~mm}$ each) were reconstructed with voxel size of $2.2 \mathrm{~mm} \mathrm{X}$ $2.0 \mathrm{~mm}$. An elliptic Region of Interest (ROI) of 
small approximately $1 \mathrm{~cm}^{2}$ and large ROI approximately $3 \mathrm{~cm}^{2}$ were placed on both liver lobes. The entire protocol lasted 15-20 minutes. Sequence optimization was done on normal volunteers.

Table (1): Clinical characteristics of studied cases.

\begin{tabular}{|c|c|c|c|}
\hline & Male $(n=18)$ & Female $(n=24)$ & $p$-value \\
\hline $\begin{array}{l}\text { Age (years): } \\
\quad \text { Mean } \pm \mathrm{SD}\end{array}$ & $49.67 \pm 2.89$ & $44.63 \pm 11.76$ & $0.084 \mathbf{a}$ \\
\hline $\begin{array}{l}\text { Height/cm: } \\
\quad \text { Mean } \pm \mathrm{SD}\end{array}$ & $178.17 \pm 5.77$ & $164.0 \pm 5.21$ & $<0.001 * \mathrm{a}$ \\
\hline $\begin{array}{l}\text { Weight }(\mathrm{kg}): \\
\quad \text { Mean } \pm \mathrm{SD}\end{array}$ & $96.17 \pm 5.23$ & $85.38 \pm 9.38$ & $<0.001 * \mathrm{a}$ \\
\hline $\begin{array}{l}B M I\left(k g / \mathrm{m}^{2}\right): \\
\quad \text { Mean } \pm \mathrm{SD}\end{array}$ & $30.30 \pm 2.23$ & $31.78 \pm 3.86$ & $0.16^{\mathbf{a}}$ \\
\hline $\begin{array}{l}\text { Hypertension N (\%) } \\
\text { DM N (\%) } \\
\text { HCV Ab N (\%) } \\
\text { HBS Ag N (\%) } \\
\text { ANA N }(\%)\end{array}$ & $\begin{array}{l}6(33.3) \\
0(0.0) \\
0 \\
0 \\
0\end{array}$ & $\begin{array}{l}6(25.0) \\
9(37.5) \\
0 \\
0 \\
3(12.5)\end{array}$ & $\begin{array}{l}0.55^{\mathrm{c}} \\
0.003^{*}\end{array}$ \\
\hline $\begin{array}{l}\text { SGPT: } \\
\quad \text { Mean } \pm \mathrm{SD}\end{array}$ & $65.67 \pm 19.35$ & $91.39 \pm 66.3$ & $0.12 \mathbf{a}$ \\
\hline $\begin{array}{l}\text { SGOT: } \\
\quad \text { Mean } \pm \mathrm{SD}\end{array}$ & $67.0 \pm 23.15$ & $74.58 \pm 41.38$ & $0.49^{a}$ \\
\hline $\begin{array}{l}\text { Serum albumin: } \\
\quad \text { Mean } \pm \text { SD }\end{array}$ & $4.12 \pm 0.47$ & $3.98 \pm 0.19$ & $0.23 \mathbf{a}$ \\
\hline $\begin{array}{l}\text { Serum bilirubin: } \\
\quad \text { Mean } \pm \text { SD }\end{array}$ & $1.09 \pm 0.023$ & $1.045 \pm 0.21$ & $0.38 \mathbf{a}$ \\
\hline $\begin{array}{l}\text { INR: } \\
\quad \text { Mean } \pm \mathrm{SD}\end{array}$ & $1.12 \pm 0.05$ & $1.14 \pm 0.11$ & $0.50 \mathbf{a}$ \\
\hline $\begin{array}{l}\text { US findings } N(\%) \text { : } \\
\text { Fatty liver }\end{array}$ & $12(66.7)$ & $21(87.5)$ & $0.10^{\mathrm{c}}$ \\
\hline $\begin{array}{l}\text { Fat fraction percent: } \\
\quad \text { Mean } \pm \text { SD } \\
\text { Median (min-max) }\end{array}$ & $\begin{array}{l}21.51 \pm 16.43 \\
15.21(5.97-48.42)\end{array}$ & $\begin{array}{l}17.99 \pm 13.1 \\
14.02(3.31-40.74)\end{array}$ & $0.45^{b}$ \\
\hline $\begin{array}{l}\text { Percent of steatosis }(b \\
\quad \text { Mean } \pm \text { SD } \\
\text { Median (min-max) }\end{array}$ & $\begin{array}{l}28.33 \pm 19.40 \\
27.5(5.0-50.0)\end{array}$ & $\begin{array}{l}25.63 \pm 15.83 \\
17.5(10.0-50.0)\end{array}$ & $0.62 \mathbf{b}$ \\
\hline $\begin{array}{l}\text { Core needle biopsy res } \\
\text { No } \\
\text { Minimal } \\
\text { Mild } \\
\text { Moderate }\end{array}$ & $\begin{array}{l}0 \\
9(50.0) \\
6(33.3) \\
3(16.7)\end{array}$ & $\begin{array}{ll}3 & (12.5) \\
7 & (29.2) \\
12 & (50.0) \\
2 & (8.3)\end{array}$ & $0.19^{d}$ \\
\hline
\end{tabular}

\section{Results}

In our study using mDixon method in fat fraction estimation yielded sensitivity of $83.3 \%$ and specificity of $85.7 \%$ with accuracy of $84.62 \%$ at cut off point of 14.545 Fig. (1) \& (Table 2).

\section{Statistical analysis and data interpretation:}

Data were fed to the computer and analyzed using IBM SPSS software package Version 22.0. Qualitative data were described using number and percent. Quantitative data were described using median (minimum and maximum) for non-parametric data and mean, standard deviation for parametric data after testing normality using Kolmogrov-Smirnov test/Shapiro-Wilk test. Significance of the obtained results was judged at the (0.05) level.

\section{Data analysis:}

\section{Qualitative data:}

- Chi-square test for comparison of 2 or more groups. 
- Monte Carlo test as correction for Chi-Square test when more than $25 \%$ of cells have count less than 5 in tables $(>2 * 2)$.

- Fischer Exact test was used as correction for ChiSquare test when more than $25 \%$ of cells have count less than 5 in $2 * 2$ tables.

Quantitative data between two groups:

Parametric tests:

- Student $t$-test was used to compare 2 independent groups.

Non parametric tests:

- Mann-Whitney U-test was used to compare 2 independent groups.

\section{Diagnostic accuracy:}

Receiver Operating Characteristic (ROC) curve analysis:

The diagnostic performance of a test, or the accuracy of a test to discriminate diseased cases from non-diseased cases is evaluated using Receiver Operating Characteristic (ROC) curve analysis. Sensitivity and Specificity were detected from the curve and PPV, NPV and accuracy were calculated through cross tabulation.

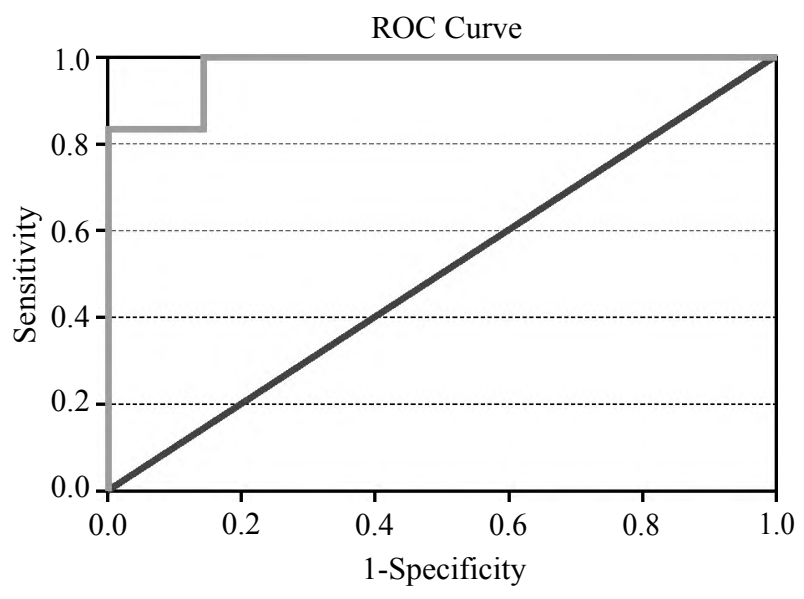

Fig. (1): ROC curve for fat fraction in differentiating steatosis.
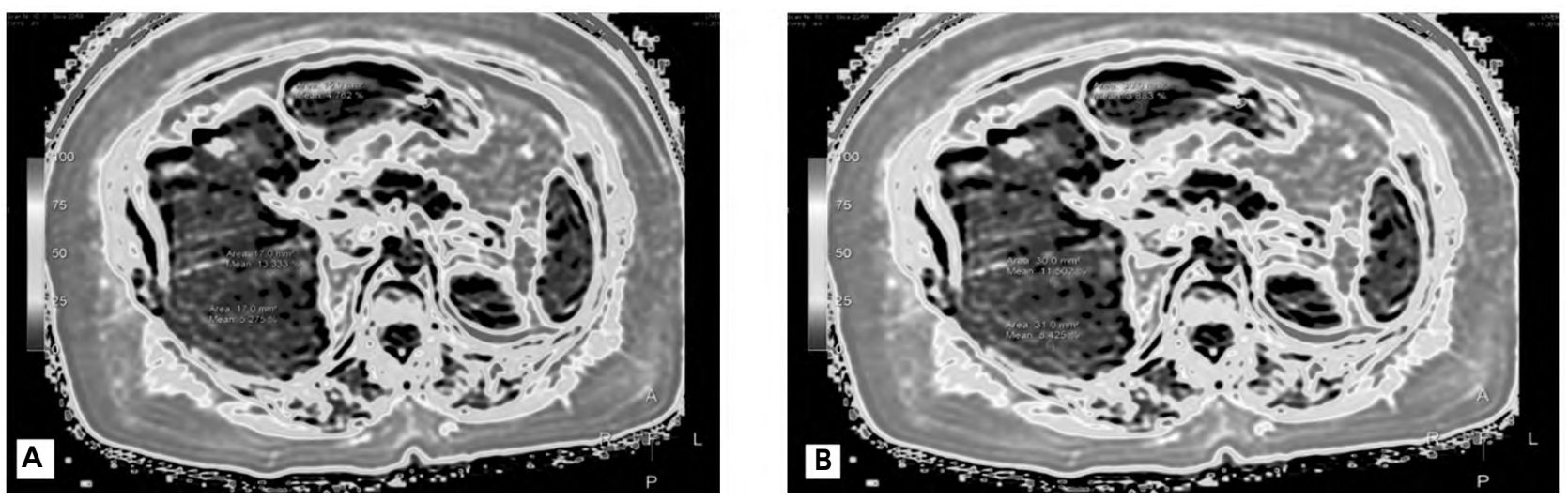

Fig. (2): Multi-echo Dixon technique in both liver lobes using small [A] and large [B] ROIs revealing different parentages ranging from $(3.88 \%-13.33 \%)$ with average percentage of $7.33 \%$. Liver biopsy revealed mild steatosis with $10 \%$ fatty infiltration.
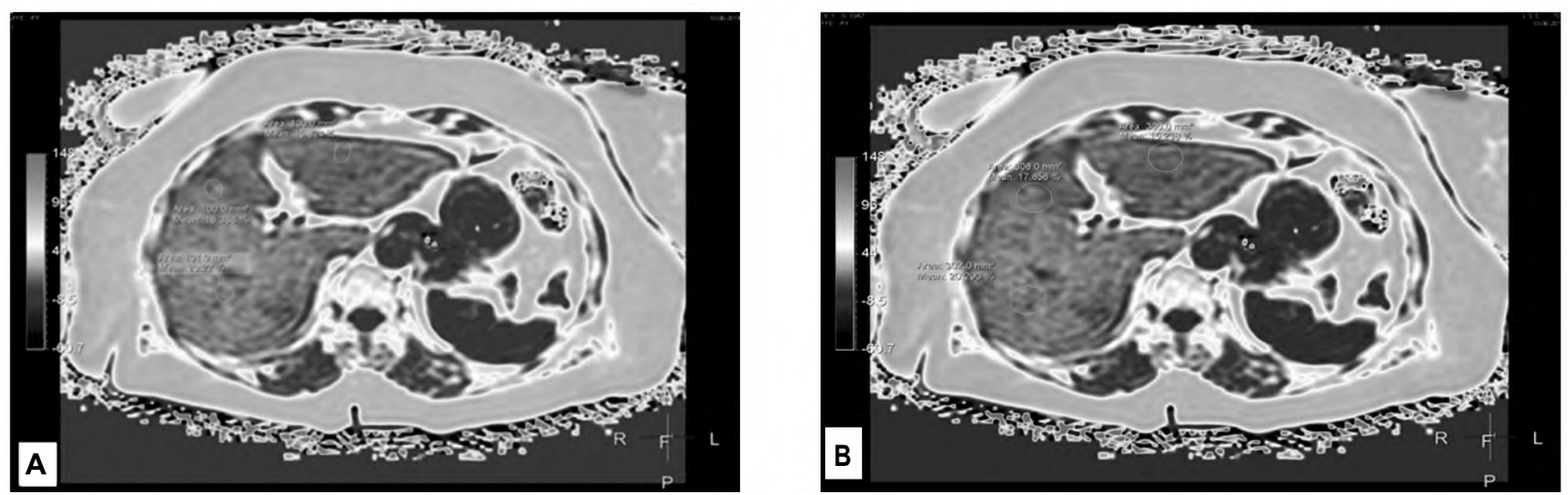

Fig. (3): Multi-echo Dixon technique in both liver lobes using small [A] and large [B] ROIs revealing different parentages ranging from $(15.82 \%-20.29 \%)$ with average percentage of $18.13 \%$. Liver biopsy revealed mild steatosis with $15 \%$ fatty infiltration. 

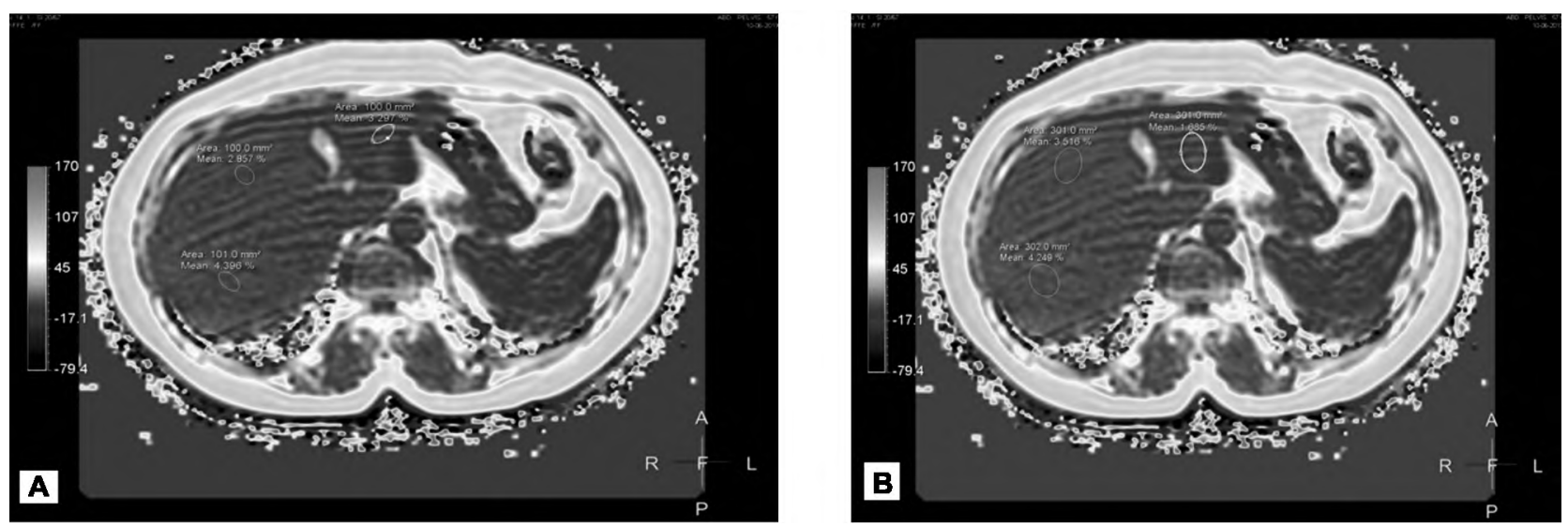

Fig. (4): Multi-echo Dixon technique in both liver lobes using small [A] and large [B] ROIs revealing different parentages ranging from (1.685\%-4.396\%) with average percentage of 3.33\%. Liver biopsy revealed minimal steatosis with $15 \%$ fatty infiltration.

Table (2): Validity of fat fraction in differentiating steatosis.

\begin{tabular}{lccccccc}
\hline & $\begin{array}{c}\text { AUC } \\
(95 \% \mathrm{CI})\end{array}$ & $\begin{array}{c}\text { Cut off } \\
\text { point }\end{array}$ & $\begin{array}{c}\text { Sensitivity } \\
(\%)\end{array}$ & $\begin{array}{c}\text { Specificity } \\
(\%)\end{array}$ & $\begin{array}{c}\text { PPV } \\
(\%)\end{array}$ & $\begin{array}{c}\text { NPV } \\
(\%)\end{array}$ & $\begin{array}{c}\text { Accuracy } \\
(\%)\end{array}$ \\
\hline Fat fraction percent & 0.976 & 14.545 & 83.3 & 85.7 & 83.3 & 85.7 & 84.62 \\
\hline PPV : Positive Predictive Value. & \multicolumn{2}{c}{ NPV : Negative Predictive Value. } & \multicolumn{2}{c}{ AUC : Area Under Curve. }
\end{tabular}

\section{Discussion}

Non-invasive estimation of liver fat is extremely important for patient selection for organ donation. MRI is considered the most accurate method for liver fat estimation amongst existing methods [12] Several different methods have been developed and introduced in MRI for the evaluation of hepatic steatosis: Chemical-Shift ImAging (CSI); spectral fat saturation; and fat-selective excitation approaches $[13,14]$. (CSI) has been the most widely used among them for evaluation of hepatic steatosis due to its to higher accuracy compared to other techniques as well as its easy applicability [15]

Dixon MR technique is utilized for liver fat estimation, it exploits the difference in precession frequencies of fat and water to decompose the MR signal into fat and water signal components. Advanced magnitude-based and complex chemical shift based MRI fat quantification techniques [12]

Dixon suggested in 1984 that four images could be obtained by simple summation of water and fat signals and subsequent subtraction, being 180 degrees out of phase (OP), from the in-phase image. The four images were named out-of-phase (OP), in phase (IP), fat-only and water only [16]. The Dixon MRI method had been widely used to analyze the characteristics of the resonance frequency difference of hydrogen atoms between fat and water molecules [17]. The Dixon method is considered as a restricted chemical shift imaging method [18] .

Data of Dixon are obtained during one or multiple breath-holds, not every patient can hold their breath for a few seconds, such as the children and severely ill patients. Compared with one breathhold, different breath-hold positions may not be correctly obtained [19]. To overcome the defect of the Dixon MR method in clinical diagnosis, the mDixon technology was developed, which uses flexible choice of echo times for fat and water separation, with the seven-peak spectral model of fat in the separation. Considering the multiple spectral peaks of fat, the seven-peak spectral model seems to improve the consistency of fat quantification, instead of the standard single-peak [18].

mDixon is a modified version of the Dixon MR method, it renders images by modifying the opposing (in) and (out) phases of the actual measurement to fit the theoretical value [20]. This method can also acquire the four images (IP, OP, fat and water images) in a single scan, but the limits of the scan parameters can be avoided perfectly [20]

In this study we found that estimation of fat fraction using mDixon method revealed sensitivity of $83.3 \%$ \& specificity of $85.7 \%$ compared to liver biopsy results. 
Kang et al., [21] found that liver MRI-PDFF (proton density fat fraction) (mDixon method) showed good correlation with histologic degree of hepatic steatosis and concluded that it is an accurate non-invasive method for quantifying hepatic fat for various hepatic disorders.

Zhao YZ et al., [22] evaluated the accuracy of mDixon in the quantification of hepatic steatosis in Chinese children and adolescents, and concluded an excellent correlation.

Bhat $\mathrm{V}$ et al., [12] confirmed the superiority of MR assessment of liver fat over CT technique found that this is consistent with the outcome of many other observers [23-26] and concluded that mDixon technology of fat estimation is not only more accurate in terms of the histological correlation but also showed more linear correlation with percentage of fat.

Idilman et al., [27] found good correlation between mdixon results for the various percentages of hepatic steatosis. PDFF differentiated moderate or severe steatosis from mild or no steatosis, with $93.0 \%$ sensitivity and $85.0 \%$ specificity, they found also that the correlation between biopsy and mDixon results was lower in patients with moderate or severe forms of hepatic steatosis compared with patients with more mild forms of steatosis.

Another studies also [28-30] reported also that Dixon in-phase and out of-phase protocols had better accuracy in patients who had mild or no fibrosis compared with patients who had moderate or severe fibrosis.

In our study correlation between accuracy of mDixon and degree of steatosis was not clear as most of our cases were of minimal or mild steatosis.

\section{Conclusion:}

This study confirms that mDixon technology of fat estimation is an accurate non-invasive method in histological correlation of liver fat percentage. Also, interpretation of the results, directly expressed as percentage of fat in the selected ROI is much easier for evaluation of different segments of the liver.

\section{References}

1- REEDER S.B., CRUITE I., HAMILTON G. and SIRLIN C.B.: Quantitative assessment of liver fat with magnetic resonance imaging and spectroscopy. Journal of Magnetic Resonance Imaging, 34 (4): 729-49, 2011.

2- DENG J., FISHBEIN M.H., RIGSBY C.K., ZHANG G., SCHOENEMAN S.E. and DONALDSON J.S.: Quantitative MRI for hepatic fat fraction and T2* measurement in pediatric patients with non-alcoholic fatty liver disease. Pediatric Radiology, 44 (11): 1379-87, 2014.

3- BANNAS P., KRAMER H., HERNANDO D., AGNI R., CUNNINGHAM A.M., MANDAL R. and REEDER S.B.: Quantitative magnetic resonance imaging of hepatic steatosis: Validation in ex vivo human livers. Hepatology, 62 (5): 1444-55, 2015.

4- ADAMS L.A., SANDERSON S., LINDOR K.D. and ANGULO P.: The histological course of nonalcoholic fatty liver disease: A longitudinal study of 103 patients with sequential liver biopsies. Journal of Hepatology, 42 (1): 132-8, 2005.

5- EKSTEDT M., FRANZÉN L.E., MATHIESEN U.L., THORELIUS L., HOLMQVIST M., BODEMAR G. and KECHAGIAS S.: Long-term follow-up of patients with NAFLD and elevated liver enzymes. Hepatology, 44 (4): 865-73, 2006.

6- ASCHA M.S., HANOUNEH I.A., LOPEZ R., TAMIMI T.A.R., FELDSTEIN A.F. and ZEIN N.N.: The incidence and risk factors of hepatocellular carcinoma in patients with nonalcoholic steatohepatitis. Hepatology, 51 (6): 1972-8, 2010

7- RATZIU V., CHARLOTTE F., HEURTIER A., GOMBERT S., GIRAL P., BRUCKERT E. and LIDO Study Group: Sampling variability of liver biopsy in nonalcoholic fatty liver disease. Gastroenterology, 128 (7): 1898-906, 2005.

8- SCHWENZER N.F., SPRINGER F., SCHRAML C., STEFAN N., MACHANN J. and SCHICK F.: Non-invasive assessment and quantification of liver steatosis by ultrasound, computed tomography and magnetic resonance. Journal of Hepatology, 51 (3): 433-45, 2009.

9- McPHERSON S., JONSSON J.R., COWIN G.J., O'ROURKE P., CLOUSTON A.D., VOLP A. and BENSON M.: Magnetic resonance imaging and spectroscopy accurately estimate the severity of steatosis provided the stage of fibrosis is considered. Journal of Hepatology, 51 (2): 389-97, 2009.

10- TANG A., TAN J., SUN M., HAMILTON G., BYDDER M., WOLFSON T. and LAVINE J.E.: Nonalcoholic fatty liver disease: MR imaging of liver proton density fat fraction to assess hepatic steatosis. Radiology, 267 (2): 422-31, 2013

11- MIDDLETON M.S., HEBA E.R., HOOKER C.A., BASHIR M.R., FOWLER K.J., SANDRASEGARAN K. and LAVINE J.E.: Agreement between magnetic resonance imaging proton density fat fraction measurements and pathologist-assigned steatosis grades of liver biopsies from adults with nonalcoholic steatohepatitis. Gastroenterology, 153 (3): 753-61, 2017.

12- BHAT V., VELANDAI S., BELLIAPPA V., ILLAYRAJA J., HALLI K.G. and GOPALAKRISHNAN G.: Quantification of liver fat with mDIXON magnetic resonance imaging, comparison with the computed tomography and the biopsy. Journal of Clinical and Diagnostic Research: JCDR, 11 (7): TC06, 2017.

13- QAYYUM A., GOH J.S., KAKAR S., YEH B.M., MERRIMAN R.B. and COAKLEY F.V.: Accuracy of liver fat quantification at MR imaging: Comparison of out-ofphase gradient-echo and fat-saturated fast spin-echo 
techniques-initial experience. Radiology, 237 (2): $507-$ 11., 2005.

14- COTLER S.J., GUZMAN G., LAYDEN-ALMER J., MAZZONE T., LAYDEN T.J. and ZHOU X.J.: Measurement of liver fat content using selective saturation at 3.0 T. Journal of Magnetic Resonance Imaging: An Official Journal of the International Society for Magnetic Resonance in Medicine, 25 (4): 743-8, 2007.

15- LEE D.H.: Imaging evaluation of non-alcoholic fatty liver disease: Focused on quantification. Clinical and Molecular Hepatology, 23 (4): 290, 2017.

16- LEE S.H., LEE Y.H., HAHN S. and SUH J.S.: Fat fraction estimation of morphologically normal lumbar vertebrae using the two-point mDixon turbo spin-echo MRI with flexible echo times and multipeak spectral model of fat: Comparison between cancer and non-cancer patients. Magnetic Resonance Imaging, 34 (8): 1114-20, 2016.

17- SOLIMAN A.S., YUAN J., VIGEN K.K., WHITE J.A., PETERS T.M. and McKENZIE C.A.: Max-IDEAL: A max-flow based approach for IDEAL water/fat separation. Magnetic Resonance in Medicine, 72 (2): 510-21, 2014.

18- LV S., JIANG S., LIU S., DONG Q., XIN Y. and XUAN S.: Noninvasive quantitative detection methods of liver fat content in nonalcoholic fatty liver disease. Journal of Clinical and Translational Hepatology, 6 (2): 217, 2018.

19- ARBOLEDA C., AGUIRRE-REYES D., GARCÍA M.P., TEJOS C., MUÑOZ L., MIQUEL J.F. and URIBE S.: Total liver fat quantification using three-dimensional respiratory self-navigated MRI sequence. Magnetic Resonance in Medicine, 76 (5): 1400-9, 2016.

20- TAKATSU Y., AKASAKA T. and MIYATI T.: The Dixon technique and the frequency-selective fat suppression technique in three-dimensional T 1 weighted MRI of the liver: a comparison of contrast-to-noise ratios of hepatocellular carcinomas-to-liver. The British Journal of Radiology, 88 (1050): 20150117, 2015.

21- KANG B.K., KIM M., SONG S.Y., JUN D.W. and JANG K.: Feasibility of modified Dixon MRI techniques for hepatic fat quantification in hepatic disorders: Validation with MRS and histology. The British Journal of Radiology, 91 (1089): 20170378, 2017.

22- ZHAO Y.Z., GAN Y.G., ZHOU J.L., LIU J.Q., CAO W.G., CHENG S.M. and ZHOU S.M.: Accuracy of multi-echo Dixon sequence in quantification of hepatic steatosis in Chinese children and adolescents. World Journal of Gastroenterology, 25 (12): 1513, 2019.
23- REEDER S.B., CRUITE I., HAMILTON G. and SIRLIN C.B.: Quantitative assessment of liver fat with magnetic resonance imaging and spectroscopy. Journal of Magnetic Resonance Imaging, 34 (4): 729-49, 2011.

24- PARK S.H., KIM P.N., KIM K.W., LEE S.W., YOON S.E., PARK S.W. and YU E.S.: Macrovesicular hepatic steatosis in living liver donors: Use of CT for quantitative and qualitative assessment. Radiology, 239 (1): 105-12, 2006.

25- PERMUTT Z., Le T.A., PETERSON M.R., SEKI E., BRENNER D.A., SIRLIN C. and LOOMBA R.: Correlation between liver histology and novel magnetic resonance imaging in adult patients with non-alcoholic fatty liver disease-MRI accurately quantifies hepatic steatosis in NAFLD. Alimentary Pharmacology \& Therapeutics, 36 (1): 22-9, 2012.

26- MARSMAN H.A., VAN WERVEN J.R., NEDERVEEN A.J., TEN KATE F.J., HEGER M., STOKER J. and VAN GULIK T.M.: Noninvasive quantification of hepatic steatosis inrats using 3.0 T 1H-magnetic resonance spectroscopy. Journal of Magnetic Resonance Imaging, 32 (1): 148-54, 2010.

27- IDILMAN I.S., ANIKTAR H., IDILMAN R., KABACAM G., SAVAS B., ELHAN A. and KARCAALTINCABA M.: Hepatic steatosis: Quantification by proton density fat fraction with MR imaging versus liver biopsy. Radiology, 267 (3): 767-75, 2013.

28- McPHERSON S., JONSSON J.R., COWIN G.J., O'ROURKE P., CLOUSTON A.D., VOLP A. and BENSON M.: Magnetic resonance imaging and spectroscopy accurately estimate the severity of steatosis provided the stage of fibrosis is considered. Journal of Hepatology, 51 (2): 389-97, 2009.

29- KALRA N., DUSEJA A., DAS A., VIRMANI V., KRISHAN DHIMAN R., CHAWLA Y. and KHANDELWAL N.: Clinical studiesChemical shift magnetic resonance imaging is helpful in detecting hepatic steatosis but not fibrosis in patients with nonalcoholic fatty liver disease (NAFLD). Annals of Hepatology, 8 (1): 21-5, 2009.

30- FRIEDRICH-RUST M., MÜLLER C., WINCKLER A., KRIENER S., HERRMANN E., HOLTMEIER J. and SARRAZIN C.: Assessment of liver fibrosis and steatosis in PBC with FibroScan, MRI, MR-spectroscopy, and serum markers. Journal of Clinical Gastroenterology, 44 (1): 58-65, 2010. 


\section{هل يمكن الإعتماد على تقنية الإم ديكسون

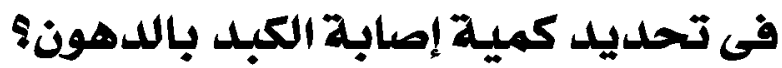

تعتبر إصابة الكبد بالدهون من آمراض الكبد الثائعة والتى قد تؤدى إلى تليف الكبد وقد يصل الآمر إلى إصابة الكبد بالآورام السرطانية.

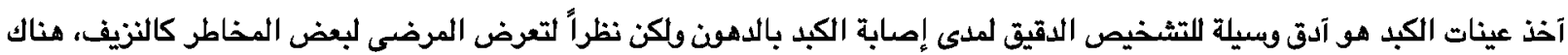

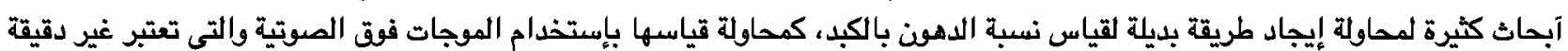

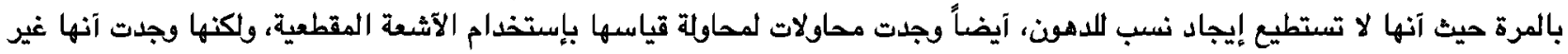
دقيقة، هذا بالإضافة إلى تعرض المريض إيباد نغطر لالآشعة المقطعية.

من هنا بدآت المحاولات لقياس نسبة دهون الكبد بإستخدام الرنين المغناطيسى بإستخدام العديد من التقنيات التهي التى تدرجت تدريجيا حتى

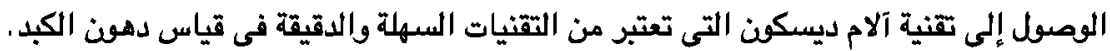

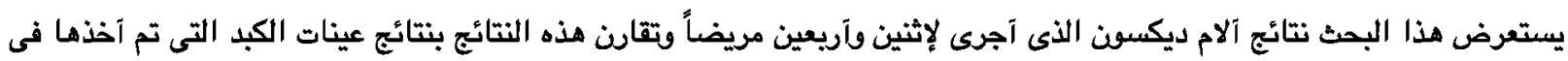

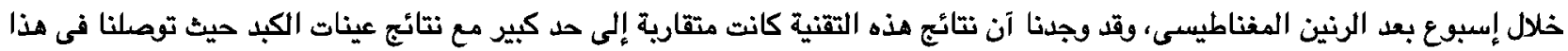

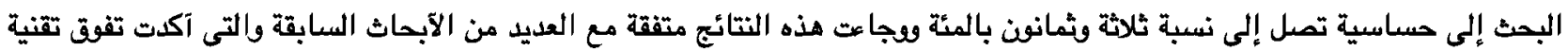

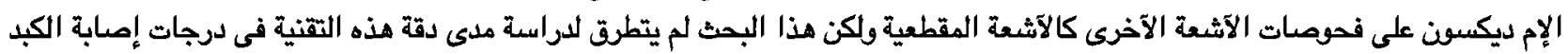

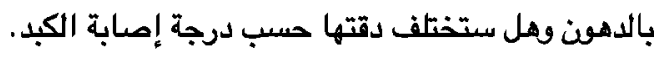

فى هذا البحث نوصى بإستخدام تقنية الإم ديكسون لتقييم مدى إصابة الكبد بالدهون حيث آنها طريقة سهلة وتعتبر دقيقة آيضاً. 